BULLETIN Bulletin hispanique

HISPANIQUE

Université Michel de Montaigne Bordeaux

$115-1 \mid 2013$

Poésie et société en Espagne : 1650-1750

\title{
Impresos poéticos de la primera mitad del siglo
} XVIII

producción y publicidad

Jean-Marc Buiguès

\section{OpenEdition}

\section{Journals}

Edición electrónica

URL: http://journals.openedition.org/bulletinhispanique/2433

DOI: $10.4000 /$ bulletinhispanique.2433

ISSN: 1775-3821

Editor

Presses universitaires de Bordeaux

Edición impresa

Fecha de publicación: 1 junio 2013

Paginación: 185-193

ISBN: 978-2-86781-898-1

ISSN: 0007-4640

Referencia electrónica

Jean-Marc Buiquès, «Impresos poéticos de la primera mitad del siglo XVIII », Bulletin hispanique [En

línea], 115-1 | 2013, Publicado el 01 junio 2016, consultado el 03 mayo 2019. URL : http://

journals.openedition.org/bulletinhispanique/2433; DOI : 10.4000/bulletinhispanique.2433 


\title{
Impresos poéticos de la primera mitad del siglo XVIII: producción y publicidad
}

\author{
JeAn-Marc Buigù̀s \\ Université Michel de Montaigne - Bordeaux 3
}

Les informations des pages de titre des imprimés de poésie - éditeur, lieu et date d'impression, données sur l'auteur, titre, etc. - permettent de dessiner la géographie de l'imprimé poétique espagnol dans la première moitié du XVIII siècle ainsi que d'ébaucher une nécessaire sociologie des poètes. Les pages de titre participent au côté des annonces d'imprimés dans la presse à la naissance de la publicité moderne.

Mots clés : édition, poésie, XVIII e siècle, auteurs, publicité.

Las informaciones de las portadas de los impresos de poesia -editor, lugar y fecha de imprenta, datos sobre el autor, titulo, etc.-permiten dibujar la geografía del impreso poético español en la primera mitad del siglo XVIII a la par que esbozar una necesaria sociologia de los poetas. Junto con los anuncios de impresos en la prensa, las portadas participan en el nacimiento de la publicidad moderna.

Palabras claves: edición, poesía, siglo XVIII, autores, publicidad.

Information on title pages of poetry printed books -the publisher, place and date of printing, facts upon the author, title, etc.- allow us to draw the geography of the Spanish poetical printed book in the first half of the eighteenth century, and thus start a necessary sociology of poets. Title pages, like advertisements for printed books in the papers, took part in the birth of modern advertising.

Keywords: publishing, poetry, Eighteenth Century, authors, advertising. 
$\mathrm{E}$ ste trabajo es la continuación del análisis empezado el año pasado y cuyos primeros resultados presenté en el coloquio de Córdoba ${ }^{1}$. Aquella primera fase del trabajo se había centrado en los anuncios de impresos de poesía de la Gaceta de Madrid. El estudio permitió reunir un total de casi 250 anuncios de impresos poéticos entre 1697 y 1750, que representaban el 5,3\% de los anuncios de impresos publicados por la Gaceta.

La segunda etapa de este trabajo, la que constituye el tema de este trabajo se ha centrado en un estudio de los impresos poéticos presentes en la base de datos elaborada en la Universidad Michel de Montaigne Bordeaux 3. El proyecto inicial que comenzó en 1993 consistía en transformar la Bibliografía de Autores Españoles del Siglo XVIII de Francisco Aguilar Piñal ${ }^{2}$ en una base informatizada ${ }^{3}$. Este primer trabajo permitió informatizar las fichas bibliográficas de los impresos de los ocho primeros volúmenes de la Bibliografía, los de obras con autoría, totalizando más de 23.000 fichas. La Bibliografía lleva una serie de limitaciones deseadas por su autor. No figuran en ella obras en latín, catalán, valenciano, vasco o gallego, de no ser que sean traducciones de obras publicadas por primera vez en castellano. Tampoco se incluyen las obras de autores anteriores reimpresas en el siglo XVIII, ya que éstas aparecen en el lugar correspondiente de la Bibliografía de la Literatura hispánica de José Simón Díaz 4 . En esta segunda fase, todavía inconclusa, se puso en marcha un programa para completar la base vaciando fuentes bibliográficas que no venían en la Bibliografía y también con los anuncios de impresos poéticos de la Gaceta de Madrid entre 1697 y $1750^{5}$. Para el periodo 1700-1750, la base arroja un total de 6270 impresos, de los cuales 260 son impresos de poesía, algo más del $4 \%$. Si comparamos este porcentaje con el de los anuncios de impresos poéticos en la Gaceta de Madrid $\left(5.28 \%^{6}\right)$, parece ser que la publicidad del anuncio de poesía es superior a su peso en la edición, lo que podría evidenciar la existencia de un público de lectores de poesía en proporción más importante que el de los lectores en general.

La primera noción que merece ser aclarada es la de impreso de poesía. Hemos elegido considerar como impreso poético en primer lugar las obras que son exclusivamente de texto(s) poético(s) (por ejemplo una edición de las obras de

1. Jean-Marc Buigues, «Los anuncios de impresos poéticos en la Gaceta de Madrid», Bulletin hispanique, 2011, Vol. 113, Número 1, pp. 331-366.

2. Francisco Aguilar Piñal, Bibliografía de autores españoles del siglo XVIII, Madrid, CSIC, 1981-1995, tomos 1 a 8. Los tomos IX y X de anónimos están pendientes de informatización. De ahí en adelante Bibliografía.

3. La base de la Universidad Michel de Montaigne Bordeaux3 se inició hace dieciocho años bajo la dirección del añorado profesor François Lopez como uno de los ejes del equipo de investigación TEMIBER. El lector encontrará una descripción del proyecto en Jean-Pierre Dedieu, «El sistema Nicanto», Bulletin Hispanique, 1997, Vol. 99, n 99-1, pp. 325-336.

4. José Simón Díaz, Bibliografía de la literatura hispánica, Madrid, Instituto Miguel de Cervantes, 1950.

5. Jean-Marc Buiguès, op. cit.

6. Jean-Marc Buiguès, op. cit., p. 338. 
Gerardo Lobo), en segundo lugar las obras cuyo título menciona expresamente la presencia de formas poéticas (en verso, soneto, coplas, etc.), en tercer lugar las obras que son de prosa pero que incluyen una obra poética (por ejemplo un romance que puede ser del mismo autor o de otro autor), y finalmente las que no mencionan la presencia de textos poéticos pero que sí sabemos que mezclan prosa y versos (como por ejemplo las reediciones de La Galatea de Cervantes). Lo que queda excluido son las obras teatrales y las obras en prosa que en sus textos preliminares, los que, según la fecunda denominación creada por Gérard Genette, se agrupan en el paratexto, y más concretamente en el paratexto autorial.

\section{Geografía del impreso de poesía}

Son 213 los impresos que mencionan su lugar de impresión. Sobre el total de 85 ciudades con imprenta que publicaron por lo menos una obra en el siglo XVIII ${ }^{7}$, las que editan poesía representarían la quinta parte: una cifra sin duda por debajo de la realidad, cifra que subraya los límites de la fuente y que se debe también en parte a la ausencia de las obras en latín y a la de datos locales. Por otra parte, estas lagunas, a pesar del carácter excepcionalmente exhaustivo de la Bibliografía, vienen confirmada por una pequeña cala en el Catálogo de la Biblioteca Nacional de España: para los años 1700-1705 son ocho los impresos de poesía que no figuran en la Bibliografía.

El análisis de las ciudades no revela diferencias fundamentales entre la producción total y la producción de impresos poéticos, salvo una excepción, la de Valencia donde efectivamente la cifra general que corresponde a su aportación a la producción nacional alcanza un $9 \%$ cuando la de impresos poéticos sólo llega al 6,6\%. La jerarquía es respetada, las seis primeras ciudades (las que superan el $6 \%$ de la producción total: Madrid, Sevilla, Barcelona, Zaragoza, Salamanca y Valencia) son las mismas, las tres siguientes (en torno al $3 \%$ ) también son las mismas (Córdoba, Pamplona y Cádiz) ${ }^{9}$.

7. Jean-Marc Buiguès, "Evolución global de la producción ", en Víctor Infantes, François Lopez, Jean-François Botrel (coord.), Historia de la edición y de la lectura en España, 1472-1914, Madrid, Fundación Germán Sánchez Ruipérez, 2003, p. 303-316.

8. El proceso de comparación que se está haciendo entre los anuncios de impresos de poesía en la Gaceta y los impresos de poesía de la Bibliografía permitirá completar esta primera visión.

9. El lector curiosos encontrará un estudio más pormenorizado de los lugares de edición de impresos de poesía en mi contribución - «El impreso poético posbarroco: Centro y periferia, impresores y formas materiales» - al Congreso Internacional «Heterodoxias y periferias en la poesía hispánica del Bajo Barroco», organizado por la Universiteit van Amsterdam los 28 y 29 de junio de 2012, pendiente de publicación en la revista Versants. 


\begin{tabular}{|l|c|c|c|c|}
\cline { 2 - 5 } \multicolumn{1}{c|}{} & \multicolumn{2}{c|}{ Impresos de poesía } & \multicolumn{2}{c|}{ Total impresos } \\
\cline { 2 - 5 } \multicolumn{1}{c|}{} & Número & $\%$ & Número & $\%$ \\
\hline Burgos & 1 & 0,5 & 24 & 0,5 \\
\hline Écija & 1 & 0,5 & 2 & 0 \\
\hline Vitoria & 1 & 0,5 & 8 & 0,2 \\
\hline Toledo & 2 & 0,9 & 29 & 0,6 \\
\hline Alcalá de Henares & 3 & 1,4 & 97 & 1,9 \\
\hline Murcia & 3 & 1,4 & 123 & 2,4 \\
\hline Palma de Mallorca & 3 & 1,4 & 61 & 1,2 \\
\hline Santiago de Compostela & 3 & 1,4 & 32 & 0,6 \\
\hline Valladolid & 4 & 1,9 & 116 & 2,3 \\
\hline Málaga & 5 & 2,3 & 46 & 0,9 \\
\hline Córdoba & 6 & 2,8 & 174 & 3,4 \\
\hline Pamplona & 6 & 2,8 & 184 & 3,6 \\
\hline Cádiz & 7 & 3,3 & 168 & 3,3 \\
\hline Valencia & 14 & 6,6 & 462 & 9 \\
\hline Salamanca & 15 & 7 & 377 & 7,3 \\
\hline Zaragoza & 17 & 8 & 435 & 8,5 \\
\hline Barcelona & 20 & 9,4 & 316 & 6,2 \\
\hline Sevilla & 20 & 9,4 & 518 & 10,1 \\
\hline Madrid & 38,5 & 1961 & 38,2 \\
\hline Total & & & 5133 & \\
\hline
\end{tabular}

\section{LOS AUTORES}

La base permite, a partir de los datos que proporciona el propio título de la obra según la costumbre editorial bien arraigada de mencionar en la portada la calidad, los títulos, las funciones o los cargos del autor, un estudio de la población de autores. La mención de este tipo de informaciones en la portada puede tener dos explicaciones, no excluyentes la una de la otra, y que en ambos casos participan del sistema del reclamo de la portada (orla, tipografía, letras a dos tintas, etc.). La primera explicación es que los datos sobre el autor que menciona la portada (nobleza, religión oficios o cargos desempeńados, etc.) son datos elegidos por el propio autor porque los considera como útiles para definir quien es y justificar su calidad de autor sea por su carrera, sus diplomas, etc. Si su mención es debida al editor o el impresor, es sin duda porque se consideran estos datos como argumentos de venta.

Las informaciones que proporcionan los títulos se han indexado en cinco campos distintos: 
- «Categ1» = campo que corresponde al estamento del autor (nobleza, clero, estado llano)

- «Categ2» = campo que recoge la información sobre el oficio o el cargo que desempeña el poeta (administración real, eclesiástica, comerciante, artesano, etc.)

- «Categ3» = se indica en él si el autor pertenece a una Academia o a una Sociedad de Amigos del País

- «Categ4» = se menciona en él la pertenencia a un Colegio Mayor

- «Categ5» = campo de indexación de los diplomas (Licenciado, doctor, etc.)

Para el periodo $1700-1750$, la base totaliza a 141 autores de los cuales 36 no mencionan dato alguno ${ }^{10}$. En la cuarta parte de las portadas el nombre del autor, cuando figura porque también hay obras anónimas (en particular en el romancero), no ofrece datos adicionales.

El clero representa el $48 \%$ del total de las portadas con datos (51 autores), el $36 \%$ del total de las portadas. El peso del clero en la producción total del mismo periodo es del $49 \%{ }^{11}$. Si consideramos que en regla general se menciona en portada la calidad eclesiástica del autor, sería el $36 \%$ la cifra más cercana a la realidad, lo que significaría que, relativamente, el clero redacta menos obras de poesía que de otro género: la poesía sería así un género impreso más laicizado. En definitiva la poesía parece constituir una excepción en la actividad autorial dado que los seglares son ampliamente mayoritarios.

Dentro el grupo el clero regular desempeńa el mayor protagonismo con el $86 \%$ del total cuando en la base sólo alcanza el $68 \%$. Las causas de semejante diferencia pueden ser son múltiples pero entre ellas destacan la importancia de las hagiografías rimadas de santos miembros de órdenes religiosas y la incidencia de la poesía circunstancial vinculada a la vida de los conventos (fiestas, tomas de velo, etc.). Los miembros del clero regular autores de poesía son miembros del clero parroquial - "presbítero», «Bachiller D. - cura más antiguo de dicha Colegial»; «Presbytero de la Congregación del oratorio de S. Felipe Neri, y Beneficiado en la misma Metropolitana ${ }^{12}$. - o miembros del alto clero como canónigos - «Doctoral que ha sido de la Santa Iglesia de Zamora»; «Canónigo de esta Santa Iglesia de Córdoba».

Los jesuitas dominan claramente con el $63 \%$ de los regulares, seguido por los carmelitas $(1 \%)$, y las demás órdenes $(0.5 \%)$ : hospitalarios de San Juan de Dios, basilios, franciscanos, mercedarios, dominicos y trinitarios. En algunos casos los religiosos desempeñan altas funciones como la de "Confesor de la reina», "Lector de Prima de Sagrada Theologia de dicho Real Convento», «Predicador de Corte en su monasterio de San Isidro del Campo, extramuros de

10. Los datos provienen del análisis del campo «Categ1».

11. La comparación se hace con los datos de Jean-Marc Buiguès, "La sociedad de los autores», en Víctor Infantes, François Lopez, Jean-François Botrel (coord.), Historia de la edición y de la lectura en España, 1472-1914, Madrid, Fundación Germán Sánchez Ruipérez, 2003, pp. $292-$ 302.

12. La ortografía es la de la portada original. 
esta ciudad de Sevilla», «Prior, que ha sido, de dicho monasterio, y en él Señor de lo espiritual y temporal de la villa de Santiponze la Vieja, y sus términos nullius Dioecesis)» o «Calificador del Santo Oficio y Theniente de Limosnero Mayor de su Magestad y su Capellán de Honor».

El problema metodológico que surge en el momento de analizar a los autores nobles proviene de la gran heterogeneidad del grupo. En efecto en muchos casos no se menciona la nobleza del autor pero sí el cargo que desempeña (por ejemplo regidor, etc.) y que lleva en sí el ser noble. Son dieciséis los autores para quienes se menciona la nobleza entre los cuales el $93 \%$ pertenece a la nobleza titulada. Los autores de poesías que pertenecen a la nobleza titulada totalizan un $10 \%$ del conjunto de autores de poesía, muy por encima del $2 \%$ de su participación en la producción total. Ser autor de poesía se ha convertido para la alta nobleza en una actividad relativamente importante lo que demuestra a la par que ya es algo que forma parte de la educación nobiliaria y que es pieza clave en las estrategias del cursus honorum y en el sistema clientelista. Estos autores son caballeros ("Cavallero que fue del Avito de Calatrava, y del Consejo de Su Magestad, en el Real de Castilla y Hazienda»; "Cavallero del Orden de Santiago y Mayordomo de Semana de Su Magestad», etc.) o nobles titulados («Marqués de Salmerón»; «Conde de la Mejorada, Procurador Mayor de dicha Ciudad», etc.).

Si consideramos que la mayor parte de las treinta y seis portadas sin datos que evidencien la pertenencia del autor a los estamentos privilegiados, corresponden a autores pecheros, la participación del estado llano se situaría entre el 20 y el $25 \%$ del total. La edición de poesía refleja también la seglarización (valga el neologismo) de la actividad creadora poética.

El segundo campo permite esbozar una tipología de los cargos o funciones desempeñadas por los autores de poesías ${ }^{13}$. La categoría más nutrida con casi la tercera parte de este conjunto es la de los militares, oficiales todos : «capitán D.,cavallero catalán»; «Brigadier de los Reales Exércitos y Coronel de el Regimiento de Jaén»; "Oficial de los Regimientos de Guardias Españolas y Walonas»; "Capitán-Teniente de Cavallos Corazos, y Comissario de las Reales Fiestas de el Rey Catholico»; «Maestro de Campo», "Intendente de la Marina, e Inspector General de las clases de marineros de Francia», etc.. La administración real también se define por una buena representación, superior al $10 \%$. Miembros y oficiales de los Reales Consejos, secretarios del rey, bibliotecarios y oficios palaciegos constituyen la inmensa mayoría del grupo: en este caso, conviene subrayar la concentración en Madrid de este tipo de autores, la capital es sede de los órganos del poder, centralización favorecida por el sistema polisinodial, y también residencia principal de la Corte. Crear poesías, y publicarlas son pues dos modalidades de la actividad cortesana y algo que al mismo tiempo puede ser útil en la carrera de los honores. La administración local (regidurías y cargos asimilados) pocas veces se menciona

13. El análisis se basa en el campo "Categ2 ". La comparación con la población total de autores de la base todavía no es posible por ser un campo en vía de indexación. 
en portada porque se sitúa en los peldaños inferiores de la implícita jerarquía de los honores y cargos.

De peso similar al grupo de los militares $(32 \%)$ es el de los autores que pertenecen al mundo de la enseńanza. Dentro del grupo, la enseñanza primaria casi no tiene representación (un «maestro de primeras letras»). Los catedráticos de Universidad totalizan el $25 \%$ y los miembros de la enseñanza que hoy día llamaríamos secundaria son los más numerosos con un $58 \%$ : pertenecen a seminarios de nobles o eclesiásticos, colegios de ordenes religiosas o de jesuitas, y a colegios mayores. Notemos también que en muchos casos se menciona la calidad de antiguo alumno de alguna que otra institución docente, casi siempre cuando la actividad poética forma parte de un acontecimiento patrocinado por dicha institución. Otra mención muy frecuente ${ }^{14}$ es la del diploma (15\%). Licenciados $(50 \%)$ y doctores $(45 \%)$ dominan el grupo donde la mención de bachiller es poco frecuente. Existe en esta población autorial una sobrerepresentación de los altos diplomados. Sin embargo en el caso de los actividades literarias organizadas por instituciones docentes muchas veces se mencionan a los alumnos : "alumno de las mismas Escuelas», «alumno de quarta classe», "Colegiales habituales del Imperial Colegio de San Miguel de ella (Granada)", "colegial en el Imperial Colegio de Nobles de Cordellás», "alumno exiguo ${ }^{15}$ de su Esclarecida Escuela Colegio Mayor de Santo Thomás de Aquino de esta Ciudad de Sevilla», "estudiante en el Real Colegio del Señor San Hermenegildo de Sevilla, y en ella presidente electo de una Academia poética, título de la gran Gran Madre y señor San Luis Gonzaga». En el último ejemplo incluso la academia es presidida por un estudiante.

Las funciones de los poetas del clero que se indican en portadas, además de la mención de su posición en la orden con las tradicionales abreviaturas «Fr.» $\mathrm{y}$ «P.», son la de capellán en la corte, de capellán castrense, de obispo, de prior, de predicador, de confesor real o de «Secretario General de su sagrada Religión», siendo también docentes algunas funciones como "Maestro de retórica» o «Maestro de escritura». Sólo una vez la portada indica una función inquisitorial: «doctor Calificador del Santo Oficio y Theniente de Limosnero Mayor de su Magestad y su Capellán de Honor». El caso es por otra parte ejemplar de la bien establecida costumbre de acumulación de títulos, cargos, funciones, etc., costumbre social a la cual contribuyen las portadas.

Las profesiones liberales en el sentido histórico de la palabra «artes liberales» suman un $10 \%$. Trátase de letrados miembros de la administración judicial - "Abogado de su Real Chancillería de Granada», «abogado de los Reales Consejos, y de la Real Audiencia de México y Promotor fiscal del Obispado de Mechoacán» - o de secretarios - «Secretario actual del Excelentísimo Señor Don Gonzalo Chacón y Orellana, dignísimo Governador, y Capitán General de la Plaza de Ceuta». Las ciencias, y en particular la medicina y la farmacia, son referencias poco presentes en la portadas, señal sin duda que la imagen del

14. La que corresponde al campo "Categ 5 ".

15. El término «exiguo» corresponde al tópico literario de la falsa modestia. 
científico, o más sencillamente del médico o del boticario, no son argumentos de venta, o que quizás también reflejo de la escasa participación de estos grupos en las actividades de creación poética. Una excepción notable sin embargo, aunque no se trata propiamente dicho de actividad de creación poética sino de elocuencia, la constituye el «Arte de eloquencia. Oratoria, Poética y Civil. Donde sale a luz el concepto, hijo del Arte, y pacto de la mente. Enséńase el methodo de hablar con elegancia y frasear con gusto, discurrir con alma y persuadir con acierto. Obra útil y necesaria a todos los curiosos. Su autor Don Antonio Campillo y Marco, Boticario, Médico y Botánico en la ilustre Villa de Albacete de el Arzobispo"...

Las» artes mecánicas» tienen escasa representación en las portadas con un artesano - «Maestro de Imbenciones y Artificios de Fuegos» - y tres músicos - un «maestro de canto y seisses de la Santa Iglesia metropolitana de Sevilla Académicos», un «capellán del choro y arpista de la Santa Iglesia de Salamanca» y un "Compositor de los Teatros de Madrid $»^{16}$.

Casi dos portadas de cada diez portadas mencionan la pertenencia a una academia. Son siete académicos de la Real Academia de la Lengua, seis de Academias y sociedades literarias, y uno de la Academia de medicina de Sevilla. Las academias vinculadas con la actividad literaria - sea institucional y real o sociabilizada en academias no regias de las cuales la mayor parte no residen en la corte - dominan claramente el conjunto. Al lado de lo que era de esperar en el reclamo autorial de las portadas - estamento, cargos, funciones, honores, diplomas - emerge un nueva categoría, la de ser miembro de una academia literaria que figura en el $5 \%$ de las portadas.

Para completar el panorama de los argumentos de los reclamos en portada hace falta mencionar el origen geográfico de los autores a pesar de su escasa presencia (el $1 \%$ del total). La mención «vecino de esta Corte» «vecino en ella» domina casi totalmente e incluso cuando el autor es de otra ciudad lo que señala es su residencia en la Corte «vecino de la ciudad de Valladolid y residente en esta Corte». Una excepción notable - «vecino de el Gran Puerto de Santa Maria» - que confirma la regla puesto que para compensar el origen provincial del autor se indica sin embargo que se trata de una «gran» localidad.

\section{ConCLUSIÓN}

La conclusión no puede ser más que parcial primero porque la base bibliográfica se está completando (faltan por ejemplo las obras manuscritas, las reediciones y las nuevas aportaciones de los estudios locales que se están llevando a cabo). Segundo porque los vínculos entre esta base y la de anuncios de impresos en la Gaceta están todavía en proceso constructivo. Sencillamente cruzando las bases ya se podría ampliar significativamente el corpus de obras de poesía : un sondeo sobre los títulos de los anuncios de poesía de la Gaceta permite

16. Se trata del músico Pablo Esteve y Grimau. 
ver que la cuarta parte de los títulos anunciados no están en la Bibliografía de Aguilar Piñal lo que permitiría para el período 1700/1750 alcanzar un total de 320 ediciones; Y finalmente porque quedan muchos autores por identificar para poder completar esta primera aproximación a la sociología de los poetas posbarrocos.

No obstante las lagunas del trabajo, algunos elementos merecen ser destacados. La publicidad autorial de los impresos de poesía tal y como figura en las portadas utiliza los mismos elementos que el resto de la edición en todo lo que toca a la caracterización del autor; la única característica original sería la mención de las academias literarias. Estos elementos - estamento, cargos, funciones, diplomas, etc. - participan en la representación, la construcción colectiva de la imagen del autor de poesías. Son al mismo tiempo elementos de venta - verdadera publicidad implícita - para el editor que demuestra así las cualidades, muchas veces institucionales, de sus autores, y elementos de promoción individual de los propios autores. Evidencian también que la población autorial de impresos poéticos presenta rasgos diferenciales del conjunto de la población autorial. La laicización y la seglarización son innegables señas de identidad de este grupo de autores. Dentro de este proceso general, algunos grupos se destacan por su mayor protagonismo: los jesuitas en el clero y la alta nobleza en el estamento nobiliario; entre las profesiones, los miembros del sector educativo y el personal administrativo y militar de la corona. En definitiva las portadas constituyen un claro reflejo de la importancia y del peso en la sociabilidad de la primera mitad del siglo XVIII de las actividades literarias y en particular poéticas, lo que no significa por lo tanto que sea algo nuevo sino más bien la prolongación de un largo proceso iniciado en el siglo XVII. 